Dexamethasone and infection in preterm babies: a controlled study

SIR,-Ng et al, in their article on dexamethasone and infection in preterm babies, conclude that 'the use of dexamethasone . . . is not associated with an increase in the incidence of infection'. 'This conclusion is unjustified for two reasons. The first of these, which they mention, is that their study is too small. To have a $50 \%$ chance of detecting an increase of one third in the infection rate the sample size required would be 69 babies in each group. ${ }^{2}$

The second reason is much more fundamental. Despite the title, this is not a controlled trial. The patients were separated into those who, in the authors' view, were going to improve, and those who were not. All of the latter group received dexamethasone. The central idea of the modern clinical trial is random allocation between control and intervention groups. ${ }^{2}$ A systematic allocation procedure of the type used here precludes any meaningful comparisons between the two groups. In other words the two groups were different from the start, and as a result no comparison between them is likely to be informative.

This is a great shame. $\mathrm{Ng}$ and colleagues have asked an important question, and put great effort into answering it. If they had done a controlled trial, perhaps with more than one neonatal unit, we might now know the answer to their question.

A STAINES

Department of Epidemiology,

ondon School of Hygiene and Tropical Medicine, Keppel Street, London WCIE 7 HT

$1 \mathrm{Ng}$ PC, Thomson MA, Dear PRF. Dexamethasone and infection in preterm babies: a contro led study. Arch Dis Child 1990;65:54-6.

2 Meinert CL. Clinical trials. Oxford: Oxford University Press, 1986.

Drs $\mathrm{Ng}$, Thomson, and Dear comment:

Dr Staines comments on two aspects of our study which he believes prevent us from drawing useful conclusions about the influence of dexamethasone on the infection rate among preterm babies, namely the lack of randomisation and the relatively small sample size. While we are as enthusiastic about large randomised trials as any epidemiologist there are some considerations which we would like to put forward in our defence.

Firstly, we believe that there is more than enough evidence for the benefit of steroid treatment in ventilator dependent very low birthweight babies to make witholding treatment from some of them in a randomised trial unjustifiable. Many neonatologists would agree with us. Short of randomisation, we tried hard to ensure that the control group was as comparable as possible with the steroid treated group, both in nature and in environmental exposure.

Secondly, the power of a study, that is the probability of its detecting a particular effect if it is present, depends on the size of the effect being sought. The size of effect that it would be important to detect is no arbitrary choice, nor one that can be legislated for by statisticians, but rather the size of effect that would influence decision making by doctors or patients. In our case the question was, how much of an increase in infection rate would steroids need to produce in order to outweigh their beneficial effect on the course of lung disease? As prolonged ventilator dependency is extremely hazardous, and as virtually all episodes of infection occurring after the first few weeks of life can be treated effectively, we embarked on our study on the premise that nothing short of a doubling of the infection rate would prevent us from using steroids in this particular group of babies. Our study had an $80 \%$ power to detect such an increase. The possibility that steroids might increase the severity of infections rather than their rate of occurrence is clearly also important but a very large study indeed would be required to assess this possibility. We saw no change in the type or severity of infection.

We would be the first to accept that the comparison that we made is imperfect but not that it is of no value. In common with most scientific studies it narrows the area of uncer tainty, and the strength of the contribution must be judged by the reader in the light of the study design, power, etc. There has been a multicentre randomised trial of dexamethasone in the UK, to which we contributed, but it has not yet been published and did not seek to look in such detail as we did at the question of infection. It may not be possible in future to justify any more randomised trials of steroids in bronchopulmonary dysplasia and the answers to questions about potential adverse side effects may have to be sought by methods such as we employed. We are sure that our study will be of value to the neonatologist debating the trade off between the potentia advantages and disadvantages of steroid treatment.

\section{Health for all children}

SIR,-The review of Health for all Children by Bax and Whitmore contains the same critical comments (and misquotations) as those already published in the Health Visitor. ${ }^{1}$ I have already responded in detail to these, and it would be superfluous to repeat the arguments here. $^{2} 3$ However, I would like to make two points.

Firstly, they comment on the 'muddle' between screening and surveillance, and emphasise that screening is not the correct term to describe regular developmental examinations. In support of their argument, they cite the work of Drillien and Drummond, which is entitled 'Development screening'! So who is muddled?

That study was indeed a major contribution to the literature on child health surveillance, and is widely quoted. Yet it offers no evidence that surveillance is worthwhile; it is essentially a descriptive report. It shows that assessments carried out by the clinical medical officers correlated with those performed at the child development centre and confirms what we already know, that children whose development is slower than average do less well than those whose development is normal or advanced.

It does not provide evidence that this particular approach to surveillance is better than any other. Perhaps more important, is the finding that those children who underwent 'development screening' did not seem to have any advantage over those who were not so assessed. "We are better at predicting than preventing'.

A substantial proportion of the resources currently devoted to community child health is consumed in the repeated examination of healthy children. Health for all Children suggested that we should limit such examinations and apply only those procedures which seem to be useful. We should be thinking about ways of targeting resources to families who really need help; instead of focusing only on a medical 'defecting-detecting' model, we need to consider ways of helping parents to manage their children more effectively-the 'health promotion' approach. There is some evidence that this could be achieved, provided that we have the skills, the commitment, and the resources to apply what is already known.

Secondly, all the members of the joint working party would acknowledge that the report has many limitations; most of these were the result of our terms of reference, which were to consider the content of surveillance rather than the ways in which it should be delivered. I now believe that we could have obtained agreement on the latter aspect as wel as the former and of course the report would have been more effective if we had addressed these issues.

Nevertheless, it should be remembered that Health for all Children was never intended to be a textbook of community paediatrics; its aim was to describe and discuss the many activities which together comprise child health surveillance. Each of these activities requires evaluation in its own right. I suggest that the question 'Is child health surveillance worthwhile?' is about as useful as 'Is surgery worthwhile?

D M B HALL Department of Child Health, St George's Hospital Medical School, Cranmer Terrace

1 Bax MCO, Whitmore K. Health for all children. Arch Dis Child 1990;65:141-2.

Hall DMB. Ringing the changes in child health. Health Visitor 1989;62:239-41.

3 Hall DMB. Health for all children and language testing. Health Visitor 1989;62:306.

4 Butler J. Child health surveillance in primary care a critical review. London: HMSO, 1989.

SIR,-Accepting that this book is a 'discussion document', 1 and that much has already been said, particularly about identifying developmental impairments, there are still a number of worrying problems. Developmental surveillance seems to be the section that has caused particular controversy as stressed by Wilson in her review, ${ }^{2}$ and indeed may have the most profound effects if this is abandoned, especially on school entry. Many children may suffer as a result if abolition is found to be the wrong decision.

It may well be that experienced practitioners will detect severe disabilities, but the children with more subtle disorders are the ones who are surely at particular risk of being unidentified. Examples are the child with a disorder of language development, who is reasonably well behaved and sits at the back of the class causing no one any trouble but making little or no scholastic progress, or the clumsy child who is thought to be lazy and would acquire motor skills like his peers if only he would try a bit harder. Experience suggests that many such children are not identified at present but may this not be an argument to improve developmental surveillance rather than abolishing it? Bax and Whitmore have been advocating this from at 